\title{
The association of multimodal analgesia and high-risk opioid discharge prescriptions in opioid-naive surgical patients
}

Erica Langnas ${ }^{1 *} \mathbb{D}$, Rosa Rodriguez-Monguio ${ }^{2,3,4}$, Yanting Luo ${ }^{4}$, Rhiannon Croci $^{5}$, R. Adams Dudley ${ }^{6}$ and Catherine L. Chen ${ }^{1,4}$

\begin{abstract}
Background: Opioids and multimodal analgesia are widely administered to manage postoperative pain. However, little is known on how improvements in inpatient pain control are correlated with high-risk (>90 daily OME) discharge opioid prescriptions for opioid naïve surgical patients.

Methods: We conducted a retrospective observational study of adult opioid-naïve patients undergoing surgery from June 2012 through December 2018 at a large academic medical center. We used multivariate logistic regression to assess whether multimodal analgesic drugs consumed in the $24 \mathrm{~h}$ prior to discharge was associated with a reduction in high-risk opioid discharge prescriptions. We identified other risk factors for receiving a high-risk discharge opioid prescription.
\end{abstract}

Results: Among the 32,511 patients, 83\% of patients were discharged with an opioid prescription. In 2013, 34.1\% of patients with a discharge opioid prescription received a high-risk prescription and this declined to 17.7\% by 2018. Use of multimodal analgesic agents during the final $24 \mathrm{~h}$ of hospitalization increased each year, with over $80 \%$ receiving at least one multimodal analgesic agent by 2018. The median OME consumed in the $24 \mathrm{~h}$ prior to discharge peaked in 2013 at 31 and steadily decreased to 19.8 by 2018. There was a significant association between the use of acetaminophen in the $24 \mathrm{~h}$ prior to discharge and a high-risk prescription at discharge $(p<0.01)$. OMEs consumed in the $24 \mathrm{~h}$ prior to discharge was a significant predictor of receiving a high-risk discharge prescription, even at low doses. Other factors associated with receipt of a high-risk discharge opioid prescription included male gender, race, history of anxiety disorder, and discharge service.

Discussion: Use of multimodal analgesia regimens in hospitalized surgical patients in the $24 \mathrm{~h}$ prior to hospital discharge increased between 2012 and 2018. Simultaneously, opioid use prior to hospital discharge decreased. Despite these gains, approximately one in five discharge prescriptions was high-risk (> 90 daily OME). In addition, we found that prescribing of discharge opioids above inpatient opioid requirements remains common in opioid naive surgical patients.

\footnotetext{
* Correspondence: Erica.Langnas@ucsf.edu

'Department of Anesthesia and Perioperative Care, University of California, San Francisco, 513 Parnassus Ave, S455, San Francisco, CA 94143, USA

Full list of author information is available at the end of the article
}

(c) The Author(s). 2021 Open Access This article is licensed under a Creative Commons Attribution 4.0 International License, which permits use, sharing, adaptation, distribution and reproduction in any medium or format, as long as you give appropriate credit to the original author(s) and the source, provide a link to the Creative Commons licence, and indicate if changes were made. The images or other third party material in this article are included in the article's Creative Commons licence, unless indicated otherwise in a credit line to the material. If material is not included in the article's Creative Commons licence and your intended use is not permitted by statutory regulation or exceeds the permitted use, you will need to obtain permission directly from the copyright holder. To view a copy of this licence, visit http://creativecommons.org/licenses/by/4.0/. The Creative Commons Public Domain Dedication waiver (http://creativecommons.org/publicdomain/zero/1.0/) applies to the data made available in this article, unless otherwise stated in a credit line to the data. 
Conclusion: Providers should account for pre-discharge opioid consumption and use of multimodal analgesia when considering the total and daily OME's that may be appropriate for an individual surgical patient on the discharge opioid prescription.

Keywords: Opioids, Multimodal analgesia, Oral morphine equivalents, Postoperative pain, Prescribing practices

\section{Introduction}

In $2018,15 \%$ of the US population filled at least one opioid prescription and about one-third of prescription opioids were obtained from surgeons (Centers for Disease Control and Prevention, 2019; Levy et al., 2015). Significant variation in opioid discharge prescribing occurs after surgery, leading to opioid prescriptions filled but ultimately left unused (Hill et al., 2017; Thiels et al., 2018). These wide variations in opioid prescribing suggest that efforts to reduce inpatient opioid consumption do not always translate into reductions in opioids prescribed at discharge (Bates et al., 2011). Excess opioids create a risk for misuse or dependence for patients, and unused opioids may be diverted into the community (Hupp, 2016).

The management of acute pain represents a critical opportunity to reduce opioid use in surgical patients. Multimodal analgesia has been shown to decrease inpatient opioid consumption for many surgical procedures (Hurley et al., 2006; Straube et al., 2005). Current pain management guidelines recommend the use of multimodal analgesic approaches in surgical patients whenever possible (Anesthesiology, 2012). It remains unclear if the opioid-sparing effects of multimodal analgesia in surgical patients are reflected in the opioid prescriptions provided at discharge.

To assess the relationship between multimodal analgesia and discharge opioid prescribing, we performed a retrospective observational cohort study using electronic medical record (EMR) data of patients having inpatient surgery at a large academic medical center between 2012 and 2018. We hypothesized that there was an increase in multimodal analgesia during the study period resulting in reductions in opioid consumption in the inpatient setting and a reduction in opioids prescribed at discharge. In addition, we investigated whether the pre-discharge pain regimen, which includes both opioid and nonopioid approaches, was associated with high-risk ( $>90$ daily OME) discharge opioid prescriptions after surgery.

\section{Methods}

\section{Study design and data source}

We conducted a retrospective observational cohort study of adult opioid-naïve patients undergoing inpatient surgery from June 2012 through December 2018 at the University of California San Francisco Medical Center. This study was approved by the UCSF IRB, which waived patient consent for acquisition of data (IRB\# 18-26728). Data was obtained by retrospective database queries of the UCSF electronic medical record (Epic Systems, Verona WI).

After extraction from an electronic data warehouse, the data were validated for accuracy with iterative chart auditing. To ensure accurate and complete data extraction, data reports were evaluated to identify inconsistencies, missingness, extreme values, and invalid codes. Discrepancy management included reviewing discrepancies, investigating the reason, and resolving them. The data extracted had no missingness. After a proper quality check and assurance, the final dataset was locked so that the dataset could not be modified and only the final clean dataset was used for analysis

\section{Study cohort}

Our study cohort was comprised of opioid-naïve patients aged 18 years and older who underwent surgery requiring a post-operative stay of at least $24 \mathrm{~h}$ after discharge from the post-anesthesia care unit (PACU), and who were ultimately discharged to either home, a skilled nursing facility or rehabilitation facility. We defined opioid-naïve as any patient without an active opioid prescription documented in their electronic medical record (EMR) starting 6 months prior to admission.

\section{Multimodal analgesia}

Multimodal analgesia refers to the administration of drugs that act by different mechanisms to reduce opioid requirements and opioid-related adverse effects when treating pain (Anesthesiology, 2012; Rosero \& Joshi, 2014). These medications can be administered via the same route or different routes (i.e., oral, intravenous, perineural). For this study, we identified multimodal analgesia as the administration of acetaminophen, NSAI DS, gabapentinoids, or nerve blocks (neuraxial or peripheral) with active infusions in the $24 \mathrm{~h}$ prior to discharge.

\section{Opioid dose calculation}

To compare pre- and post-discharge opioid use, we converted all IV, PO, regional, and neuraxial opioid consumed in the $24 \mathrm{~h}$ leading up to hospital discharge into oral morphine milligram equivalents (OME) using the 2018 UCSF Pain Management Committee's opioid equivalent algorithm (University of California San 
Francisco, Pain Management Committee's, 2018). The opioid dosage on the discharge opioid prescription was also converted into OMEs using the same opioid conversion ratios. The conversion to daily OMEs included the medication type, dose, route, frequency, and total number of pills in the discharge prescription. The daily dose on the discharge opioid prescription was defined as the maximum allowable dose in a $24-\mathrm{h}$ period according to the written prescription.

\section{Definition of high-risk prescription}

The risk of opioid-related adverse effects is directly associated with the maximum daily oral morphine equivalents prescribed (Bohnert et al., 2011; Brat et al., 2018). Consistent with CDC recommendations, we defined a high-risk prescription as a discharge opioid prescription exceeding 90 OME per day, which has been associated with an increased risk of opioid-related adverse effects, including overdose death (Dowell et al., 2016).

\section{Covariates}

We assessed other variables that may be associated with the discharge opioid prescription, including patient demographic characteristics, history of substance use disorder, depression, anxiety, discharge service, year of surgical admission, hospital length of stay (LOS), and returning to the operating room during the admission. Comorbid conditions were identified using ICD-9 and ICD-10 diagnosis codes listed in the diagnosis fields or the patient problem list (Table S1).

\section{Statistical analysis}

We assessed the relationship between each patient's 24$\mathrm{h}$ pre-discharge pain regimen and the quantity of opioid and non-opioid analgesics prescribed at hospital discharge. We measured inpatient multimodal analgesia use and inpatient opioid consumption in the $24 \mathrm{~h}$ prior to discharge from 2012 to 2018 (Fig. 1a and b, respectively). We calculated the daily OME written on the discharge prescription and the percent of patients receiving a discharge opioid prescription between 2012 and 2018 (Fig. 2a). We identified the percent of discharge opioid prescriptions with a dose exceeding 90 daily OME between 2012 and 2018 (Fig. 2b). We compared the dose written on the discharge opioid prescription with the total OME consumed in the $24 \mathrm{~h}$ prior to discharge between 2012 and 2018 (Fig. 3). We also identified patients who were prescribed opioids at hospital discharge who did not take any opioid analgesics during their last $24 \mathrm{~h}$ of hospital stay. Means, medians, and interquartile ranges (IQR) were used to visualize annual trends in multimodal analgesia, opioid consumption, and opioid prescribing patterns. We used multivariable logistic regression analysis to assess whether multimodal analgesic drugs consumed in the $24 \mathrm{~h}$ prior to discharge was associated with a reduction in high-risk ( $>90$ daily OME) discharge opioid prescribing. We also identified other potential predictors for receiving a high-risk discharge opioid prescription (Table 2).

\section{Results}

We identified 32,511 patients meeting inclusion criteria during the study period. The mean age was 55 years (SD 17 ), and $47.6 \%$ were male. The median LOS was 3.4 days (IQR 2.21, 6.25). Overall, 83\% of patients were discharged with an opioid prescription (Table 1).

\section{Pain medication consumption prior to discharge}

The median OME administered in the $24 \mathrm{~h}$ prior to discharge peaked in 2013 at 31 OME (IQR 7.5, 71.5) and steadily decreased to 19.8 OME by 2018 (IQR 0, 52.5) (Fig. 1b). Use of multimodal analgesic agents during the final $24 \mathrm{~h}$ of hospitalization increased every year and peaked in 2018 , with $80.3 \%, 34.1 \%$, and $27.1 \%$ of patients consuming acetaminophen, gabapentinoids, or NSAIDs, respectively (Fig. 1a). Excluding patients with nerve catheters or epidurals, $20.2 \%$ of patients did not consume any opioid analgesics in the $24 \mathrm{~h}$ prior to hospital discharge in 2012 . This percentage increased to $30.62 \%$ by 2018 (Fig. 1b).

\section{Pain medication prescribed at discharge}

The percent of patients being discharged with an opioid peaked in 2016 at $85.8 \%$ of patients, and decreased to $77.3 \%$ in 2018 , while daily OME on the discharge prescription peaked in 2014 with a median of 90 (IQR 50,120 ) and decreased to 60 (IQR 45,90) in 2018 (Fig. 2a). In $2013,34.1 \%$ of patients with a discharge opioid prescription received a high-risk prescription; this percentage declined to $17.7 \%$ by 2018 (Fig. 2b). The mean difference between total daily OME on discharge prescription and total daily OME consumed in the prior 24 $\mathrm{h}$ was positive each year. In other words, more daily OMEs were written on the discharge prescription than consumed in the day prior to discharge in each year of our study. The mean difference peaked in 2012 with a mean of 30 additional OME in the discharge prescription and decreased to 17 by 2018 (Fig. 3). We found that $58.7 \%$ of the 8052 patients who did not use opioids or nerve catheters in the last $24 \mathrm{~h}$ prior to discharge were prescribed opioids at hospital discharge. The median daily OME written on the discharge prescription for this cohort was 30 (IQR 0.80). Of the patients who did not use opioids or nerve catheters in the last $24 \mathrm{~h}, 10 \%$ received a high-risk discharge prescription of greater than 90 daily OME. 


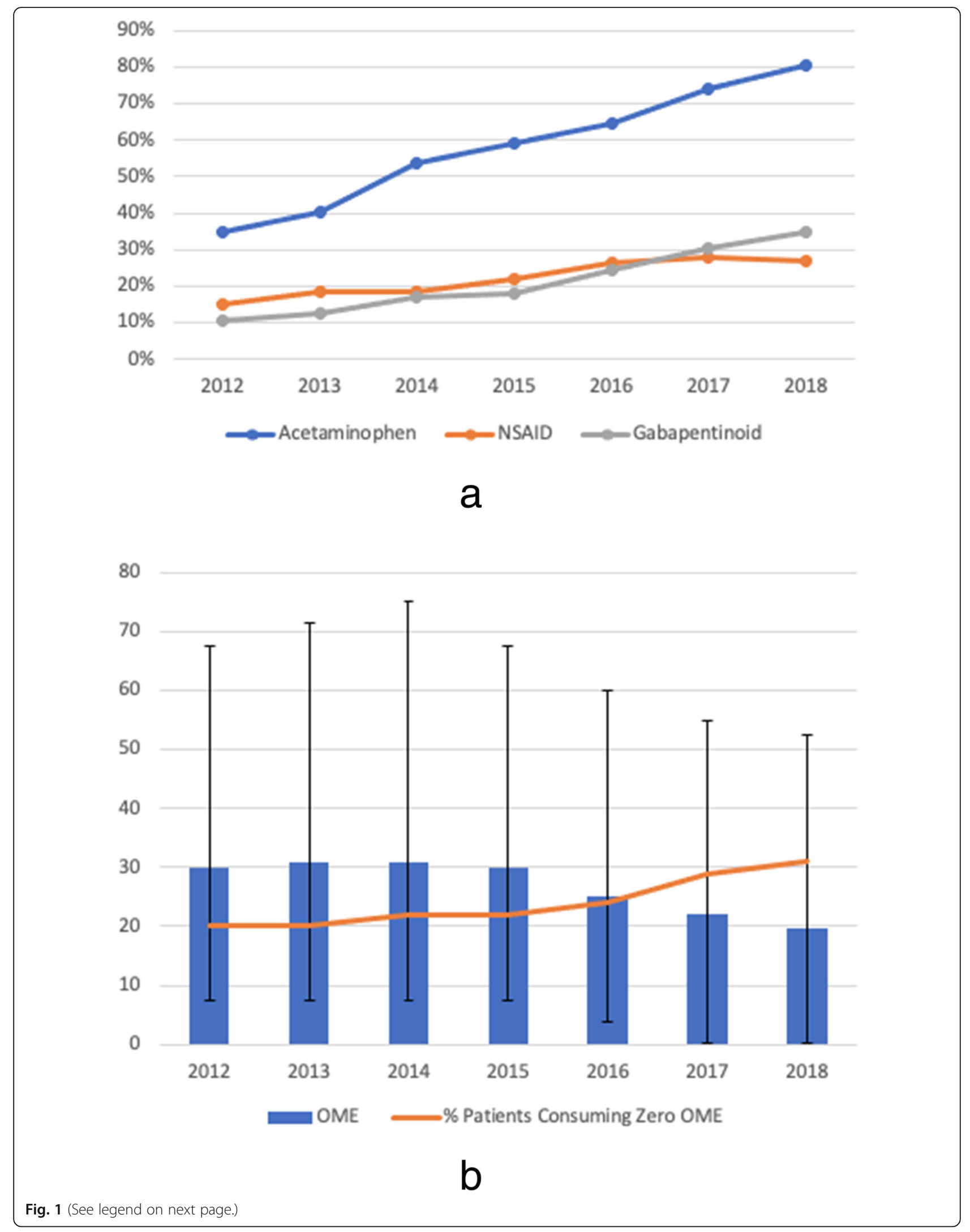


(See figure on previous page.)

Fig. 1 Opioid and non-opioid pain medication consumption $24 \mathrm{~h}$ prior to discharge by year. a Percentage of patients who consumed acetaminophen, non-steroidal anti-inflammatory drugs (NSAID), or gabapentinoid in the $24 \mathrm{~h}$ prior to discharge by year. $\mathbf{b}$ Median and interquartile ranges of oral morphine equivalents (OME) consumed in $24 \mathrm{~h}$ prior to discharge by year and percent of patients consuming zero opioids in the $24 \mathrm{~h}$ prior to discharge

Predictors for high-risk opioid prescription at discharge Consumption of gabapentinoids or NSAIDs prior to discharge was not associated with a reduction in the likelihood of receiving a high-risk opioid prescription (Table 2). There was a significant association between the use of acetaminophen in the $24 \mathrm{~h}$ prior to discharge and a high-risk prescription at discharge [(AOR), 1.108; 95\% CI, 1.041-1.170]. Discharge prescription of acetaminophen was also associated with an increased likelihood of a high-risk discharge opioid prescription [(AOR) 1.104; 95\% CI 1.029-1.173], along with discharge prescription of gabapentinoids [(AOR) 1.486; 95\% CI, 1.42-1.54]. Total OMEs consumed in the 24 $\mathrm{h}$ prior to discharge was a significant predictor of receiving a high-risk discharge prescription, even at low doses. Other patient level factors associated with receipt of a high-risk discharge opioid prescription included male gender [(AOR) 1.132; 95\% CI, 1.060-1.209], race, and history of anxiety disorder [(AOR) 2.64; 95\% CI, 1.414-4.868]. The discharge services with the highest likelihood of writing high-risk discharge prescriptions were orthopedics [(AOR) 4.662; 95\% CI, 4.138-5.252] and thoracic surgery [(AOR) 3.122; 95\% CI, 2.450-3.978]. Additional significant predictors included discharge year, with 2013 having the highest association with a high-risk prescription ([AOR] 3.189, 95\% CI, 2.818-

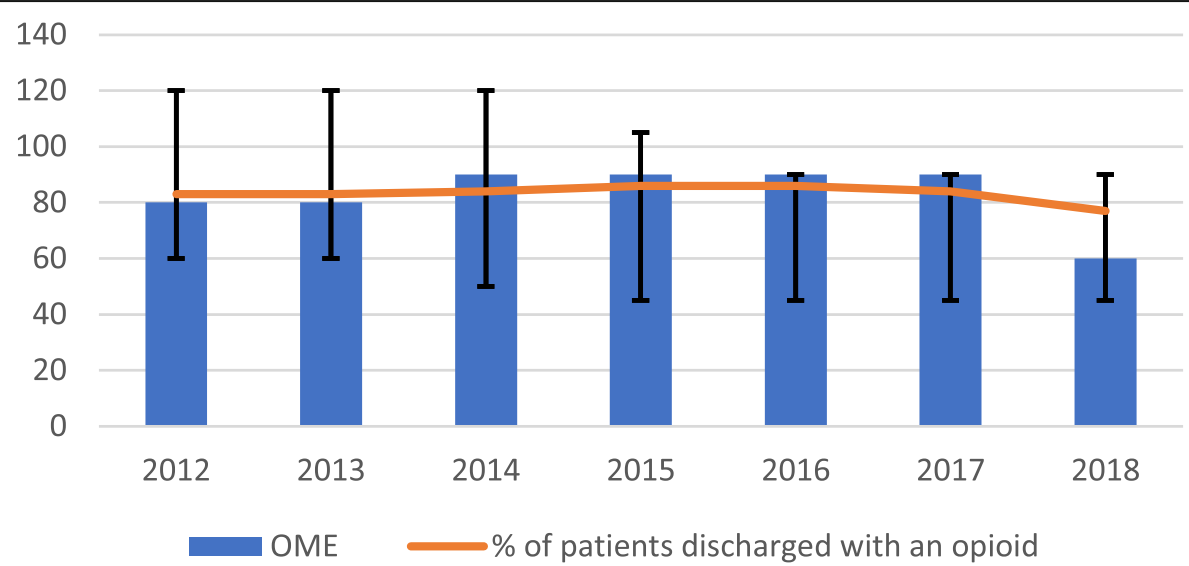

a

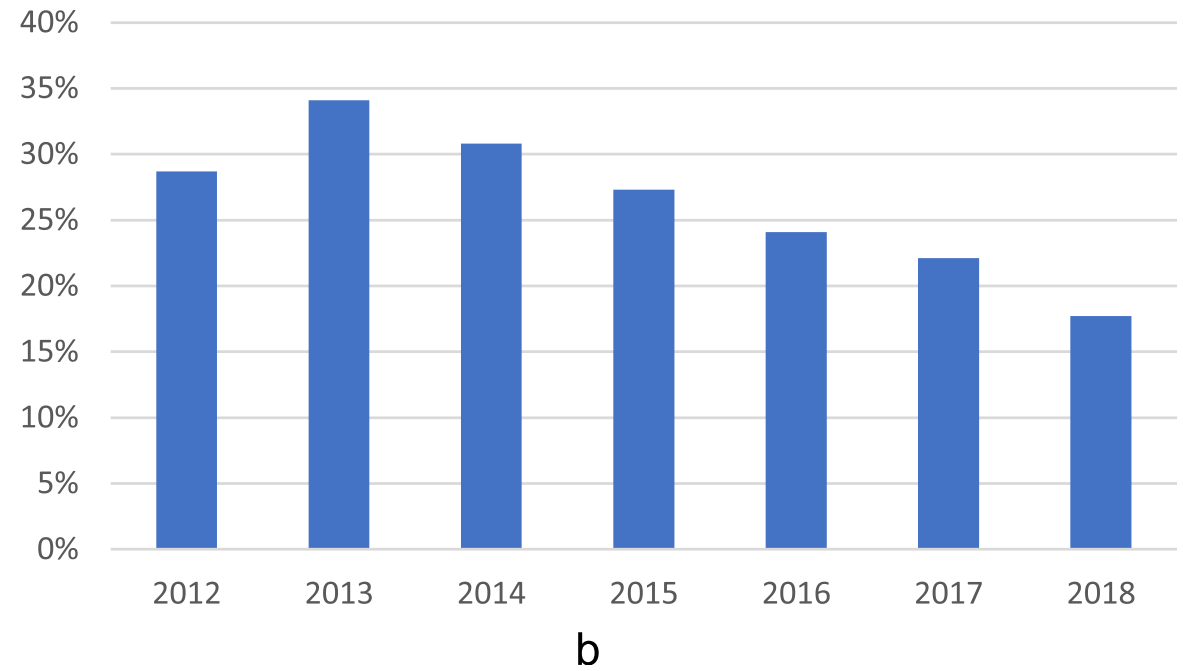

Fig. 2 Opioids prescribed at discharge by year. a Percent of patients discharged with an opioid and median and interquartile ranges of daily oral morphine equivalents (OME) on discharge prescription by year. b Percent of discharge prescriptions that are high-risk (>90 daily OME) 


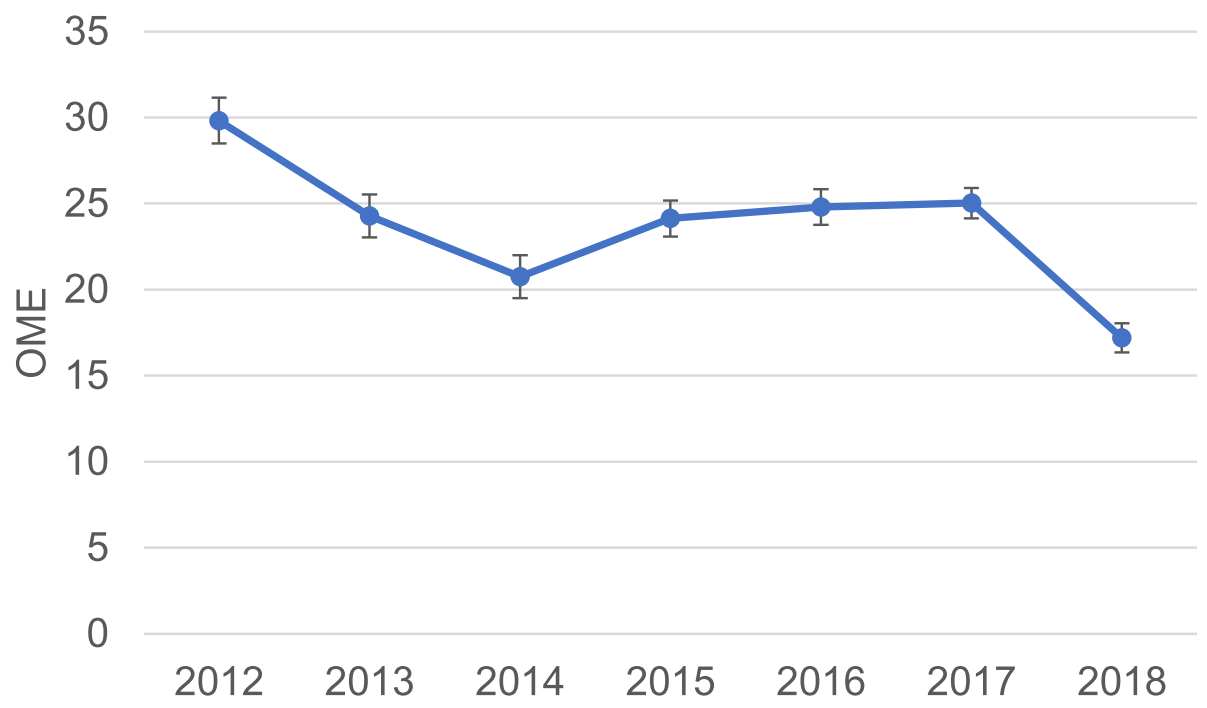

Fig. 3 The mean difference, $+/$ - standard error of the mean of daily oral morphine equivalents (OME) on discharge prescription compared to OME consumed in the $24 \mathrm{~h}$ prior to discharge by year

Table 1 Demographic and clinical attributes of study cohort

\begin{tabular}{|c|c|c|}
\hline & Patient encounters $(n=32,511)$ & \\
\hline Age, mean (sd) & $55(17)$ & \\
\hline Gender & $\%$ & $n$ \\
\hline male & $47.60 \%$ & 15459 \\
\hline female & $52.50 \%$ & 17050 \\
\hline Race & $\%$ & $n$ \\
\hline White & $60.20 \%$ & 19572 \\
\hline Black & $5.32 \%$ & 1730 \\
\hline Asian & $13.63 \%$ & 4431 \\
\hline American Indian or Alaska Native & $0.53 \%$ & 172 \\
\hline Native Hawaii or Pacific Islander & $1.27 \%$ & 413 \\
\hline other & $16.48 \%$ & 5358 \\
\hline unknown & $2.57 \%$ & 835 \\
\hline Surgical admissions per year & $\%$ & $n$ \\
\hline 2012 & $6.62 \%$ & 2153 \\
\hline 2013 & $13.10 \%$ & 4259 \\
\hline 2014 & $13.20 \%$ & 4292 \\
\hline 2015 & $15.52 \%$ & 5045 \\
\hline 2016 & $16.51 \%$ & 5367 \\
\hline 2017 & $17.37 \%$ & 5647 \\
\hline 2018 & $17.68 \%$ & 5748 \\
\hline Length of stay in days, median (IQR) & $3.42(2.21-6.25)$ & \\
\hline Return to operating room during surgical admission & $7.76 \%$ & 2522 \\
\hline Epidural or peripheral nerve catheter $24 \mathrm{~h}$ prior to discharge & $6.77 \%$ & 2201 \\
\hline Patients discharged with opioid prescription & $83.12 \%$ & 27025 \\
\hline
\end{tabular}


Table 2 Predictors of receiving a high-risk discharge opioid prescription

\begin{tabular}{|c|c|c|c|c|}
\hline & AOR & Lower CL & Upper CL & $P$ value \\
\hline \multicolumn{5}{|l|}{ Sex (reference: female) } \\
\hline Male & 1.132 & 1.06 & 1.209 & 0.0032 \\
\hline \multicolumn{5}{|l|}{ Race (reference: White) } \\
\hline Black & 0.782 & 0.675 & 0.907 & \multirow[t]{6}{*}{0.0004} \\
\hline Asian & 0.837 & 0.754 & 0.928 & \\
\hline American Indian or Alaska Native & 0.739 & 0.486 & 1.124 & \\
\hline Native Hawaiian or Pacific Islander & 0.882 & 0.651 & 1.195 & \\
\hline other & 0.907 & 0.831 & 0.991 & \\
\hline unknown & 0.854 & 0.701 & 1.041 & \\
\hline \multicolumn{5}{|l|}{ Discharge year (reference: 2018) } \\
\hline 2012 & 2.405 & 2.072 & 2.791 & \multirow[t]{6}{*}{$<.0001$} \\
\hline 2013 & 3.189 & 2.818 & 3.61 & \\
\hline 2014 & 2.507 & 2.218 & 2.833 & \\
\hline 2015 & 2.355 & 2.092 & 2.651 & \\
\hline 2016 & 1.991 & 1.772 & 2.237 & \\
\hline 2017 & 1.722 & 1.534 & 1.934 & \\
\hline \multicolumn{5}{|l|}{ Length of stay in days (reference $<3$ ) } \\
\hline 3 to 6 & 1.837 & 1.702 & 1.983 & \multirow[t]{2}{*}{$<.0001$} \\
\hline$>6$ & 2.158 & 1.968 & 2.366 & \\
\hline History of substance use disorder & 0.971 & 0.734 & 1.284 & 0.8348 \\
\hline History of depression & 0.942 & 0.825 & 1.075 & 0.3744 \\
\hline History of anxiety & 2.625 & 1.415 & 4.868 & 0.0022 \\
\hline Peripheral nerve catheter or epidural used $24 \mathrm{~h}$ prior to discharge & 1.027 & 0.916 & 1.151 & 0.6502 \\
\hline \multicolumn{5}{|l|}{ Multimodal consumed $24 \mathrm{~h}$ prior to discharge $($ reference $=\mathrm{no})$} \\
\hline acetaminophen & 1.108 & 1.041 & 1.170 & 0.0021 \\
\hline NSAID & 1.016 & 0.927 & 1.113 & 0.7392 \\
\hline gabapentinoids & 1.027 & 0.92 & 1.146 & 0.6324 \\
\hline \multicolumn{5}{|l|}{ Multimodal prescribed at discharge $($ reference $=$ no $)$} \\
\hline acetaminophen & 1.104 & 1.029 & 1.173 & 0.0075 \\
\hline NSAID & 0.927 & 0.813 & 1.056 & 0.2545 \\
\hline gabapentinoids & 1.486 & 1.420 & 1.544 & $<.0001$ \\
\hline \multicolumn{5}{|l|}{ Total OME consumed $24 \mathrm{~h}$ prior to discharge (reference $=0$ ) } \\
\hline$>0-30$ & 1.577 & 1.421 & 1.75 & \multirow[t]{4}{*}{$<.0001$} \\
\hline $30-60$ & 3.057 & 2.749 & 3.4 & \\
\hline $60-90$ & 5.141 & 4.58 & 5.77 & \\
\hline $90+$ & 10.431 & 9.332 & 11.659 & \\
\hline \multicolumn{5}{|l|}{ Days of opioids on discharge prescription (reference $\leq 7$ days) } \\
\hline$>7$ days & 0.675 & 0.628 & 0.726 & $<.0001$ \\
\hline Return to operating room during surgical admission & 0.917 & 0.812 & 1.036 & 0.1658 \\
\hline \multicolumn{5}{|l|}{ Discharge Service (reference General surgery) } \\
\hline Orthopedics & 4.662 & 4.138 & 5.252 & \multirow[t]{4}{*}{$<.0001$} \\
\hline Thoracic surgery & 3.122 & 2.45 & 3.978 & \\
\hline Cardiac surgery & 2.766 & 2.304 & 3.32 & \\
\hline Urology & 2.165 & 1.897 & 2.472 & \\
\hline
\end{tabular}


Table 2 Predictors of receiving a high-risk discharge opioid prescription (Continued)

\begin{tabular}{|c|c|c|c|c|}
\hline & AOR & Lower CL & Upper CL & $P$ value \\
\hline Critical care medicine & 1.832 & 0.737 & 4.557 & \\
\hline Neurosurgery & 1.609 & 1.442 & 1.794 & \\
\hline Gynecologic oncology & 1.368 & 1.115 & 1.679 & \\
\hline Malignant hematology & 1.278 & 0.717 & 2.278 & \\
\hline Advanced heart failure & 0.879 & 0.263 & 2.94 & \\
\hline Vascular surgery & 0.874 & 0.707 & 1.081 & \\
\hline Otolaryngology, head and neck surgery & 0.837 & 0.682 & 1.028 & \\
\hline Advanced lung disease & 0.788 & 0.156 & 3.988 & \\
\hline Plastic surgery & 0.783 & 0.581 & 1.055 & \\
\hline Colorectal surgery & 0.756 & 0.606 & 0.943 & \\
\hline Gynecology & 0.695 & 0.46 & 1.051 & \\
\hline Hospital medicine & 0.549 & 0.412 & 0.733 & \\
\hline Transplant surgery & 0.516 & 0.305 & 0.871 & \\
\hline Liver transplant & 0.457 & 0.354 & 0.592 & \\
\hline Pediatric service & 0.449 & 0.301 & 0.671 & \\
\hline Obstetrics & 0.404 & 0.32 & 0.509 & \\
\hline Kidney transplant & 0.397 & 0.322 & 0.49 & \\
\hline Neurovascular & 0.275 & 0.096 & 0.788 & \\
\hline Ophthalmology & 0.178 & 0.023 & 1.353 & \\
\hline Neurology & 0.131 & 0.032 & 0.54 & \\
\hline Oral and maxillofacial surgery & 0.128 & 0.052 & 0.316 & \\
\hline Cardiology & 0.059 & 0.008 & 0.427 & \\
\hline
\end{tabular}

3.610], and patient length of stay, with length $>6$ days associated with a high-risk prescription [(AOR) 2.158; 95\% CI, $1.968-2.366]$.

\section{Discussion}

We found a significant increase in the use of multimodal analgesia regimens in the $24 \mathrm{~h}$ prior to discharge in the years 2012-2018, and this trend coincided with a reduction in $24 \mathrm{~h}$ pre-discharge opioid consumption, and a reduction in high-risk opioid prescriptions. These findings are consistent with prior studies investigating the effects of multimodal in surgical patients (Hurley et al., 2006; Straube et al., 2005; Militsakh et al., 2018). However, despite these reductions, almost $80 \%$ of patients still received an opioid prescription at hospital discharge. In addition, we identified a gap between the gains in inpatient pain management and the gains of safer opioid prescribing practices at hospital discharge in the surgical patient population. Our results showed that approximately one-fifth of patients received a high-risk prescription known for causing opioid-related adverse events.

Prior studies comparing opioid use in the $24 \mathrm{~h}$ predischarge to discharge opioids have not explored the potential opioid-sparing effect of multimodal analgesia (Chen et al., 2018). Interestingly, our study found that acetaminophen, both consumption prior to discharge and inclusion on the discharge prescription, as well as gabapentinoid prescription at discharge, were associated with an increased likelihood of a high-risk discharge prescription. We suspect that patients who have more pain or require more opioids prior to discharge are being more aggressively optimized by adding adjuncts to help mitigate opioid needs. Other potential explanatory factors that increased the odds of receiving a high-risk prescription included discharge service, male gender, white race, prolonged length of stay, and having a history of anxiety.

The risk for an opioid related adverse event is directly related to the dose prescribed (Bohnert et al., 2011; Brat et al., 2018). Notably, patients who consumed even low doses of opioids prior to discharge were also more likely to receive a high-risk opioid prescription, and this risk increased in a dose-dependent fashion according to the amount consumed immediately prior to discharge. Therefore, initiatives aimed at reducing inpatient opioid consumption combined with tools that promote patient specific opioid prescriptions may have the potential to reduce unnecessary high-risk discharge opioid prescribing as well. Any effort to reduce inpatient opioid consumption should ensure that pain is appropriately 
managed with a balanced combination of both opioid and non-opioid analgesics.

Our findings highlight lack of consistency in opioid prescribing after surgery in opioid-naïve patients. We found $58.7 \%$ of patients who consumed no opioids in their last $24 \mathrm{~h}$ prior to discharge and had no nerve block still received opioids. Patients received excess opioids on the discharge prescription, averaging 24 daily OMEs more than what was consumed during their last day of hospitalization. This disconnect between inpatient opioid requirements and the amounts written on the discharge opioid prescription suggests that prescribers have not adapted their discharge prescribing practices to account for individual patient opioid needs after discharge, and these prescribed amounts may be driven by other factors.

A variety of factors affect prescribing behaviors, including diagnostic skills, clinical judgment, drug knowledge, institutional protocols and policies, financial incentives, and motivation to remain up to date on medical practices, which are variable among practitioners (Stern \& Trajtenberg, 1998). To address these complex variations in opioid prescribing practices, studies have identified benefits of individualized opioid prescribing and as a result consensus statements have emerged emphasizing patient-centered approaches for discharge opioid prescriptions to reduce over prescribing for surgical patients (Levy et al., 2021). Future initiatives and policies should focus on providing an individualized approach in determining discharge pain medications for surgical patients in order to provide safer opioid prescriptions and avoid inadvertent harm.

\section{Strengths and limitations}

Strengths of this study include the large sample size spanning 6 years of surgical prescribing across all surgical specialties at our academic hospital system and the inclusion of a variety of multimodal analgesic approaches, which have not been addressed in prior studies on discharge opioid prescribing in surgical patients. However, as a single-center study, the findings may not represent prescribing practices at non-academic hospitals or different geographical regions. Finally, the retrospective observational study design using electronic health records limits our ability to assert a causal relationship between the explanatory factors in our model and high-risk discharge opioid prescribing practices. In addition, our study was conducted during a time of increasing evidence of harm associated with unsafe opioid prescribing practices along with the introduction of national, state, and institutional level opioid prescribing initiatives, which may have contributed to the changes in opioid prescribing practices we found. Despite these limitations, this study sheds light on several important discrepancies between opioid-sparing inpatient pain management recommendations and discharge opioid prescribing practices in surgical patients.

\section{Conclusion}

Use of multimodal analgesia regimens in hospitalized surgical patients in the $24 \mathrm{~h}$ prior to hospital discharge increased between 2012 and 2018. Simultaneously, opioid use prior to hospital discharge decreased. Despite these gains, approximately one in five discharge prescriptions was high-risk ( $>90$ daily OME), and prescribing discharge opioids with a total OME above the patient's inpatient opioid requirement remained a common occurrence. Providers should account for predischarge opioid consumption and the concomitant use of multimodal analgesia when considering the total and daily OMEs on the discharge prescription for individual surgical patients.

\section{Abbreviations}

OME: Oral morphine equivalent; PACU: Post anesthesia care unit;

EMR: Electronic medical record; NSAID: Nonsteroidal anti-inflammatory drug

\section{Supplementary Information}

The online version contains supplementary material available at https://doi. org/10.1186/s13741-021-00230-3.

Additional file 1: Table S1: ICD codes for depression anxiety and substance use disorder

Acknowledgements

We thank the editor and reviewers for their insightful suggestions.

Authors' contributions

EL: This author helped with study conception and design, acquisition of data, analysis and interpretation of data, drafting of manuscript, and critical revisions. RRM: This author helped with study conception and design, analysis and interpretation of data, drafting of manuscript, and critical revisions. YL: This author helped with study conception and design, analysis and interpretation of data, and revise the manuscript. RC: This author helped with acquisition of data, analysis and interpretation of data, and revise the manuscript. AD: This author helped with study conception and design, analysis and interpretation of data, and critical revisions. CC: This author helped with study conception and design, analysis and interpretation of data, drafting of manuscript, and critical revisions. All authors read and approved the final manuscript.

Funding

None to disclose.

Availability of data and materials

Raw large-scale electronic medical record data were generated at our institution. Derived data supporting the findings of this study are available from the corresponding author on reasonable request with permission of IRB.

\section{Declarations}

Ethics approval and consent to participate

This study was approved by the UCSF IRB, which waived patient consent for acquisition of data (IRB\# 18-26728).

Consent for publication

Not applicable. 


\section{Competing interests}

The authors declare no competing interests.

\section{Author details}

'Department of Anesthesia and Perioperative Care, University of California, San Francisco, 513 Parnassus Ave, S455, San Francisco, CA 94143, USA. 2Department of Clinical Pharmacy, University of California, San Francisco, San Francisco, USA. ${ }^{3}$ Medication Outcomes Center, University of California, San Francisco, San Francisco, USA. ${ }^{4}$ Philip R. Lee Institute for Health Policy Studies at the University of California, San Francisco, San Francisco, USA. ${ }^{5}$ UCSF Health Informatics, University of California, San Francisco, San Francisco, USA.

${ }^{6}$ Department of Medicine, University of Minnesota, Minneapolis, USA.

Received: 16 August 2021 Accepted: 1 November 2021

Published online: 15 December 2021

\section{References}

Practice Guidelines for Acute Pain Management in the Perioperative Setting: an updated report by the American Society of Anesthesiologists task force on acute pain management. Anesthesiology. 2012;116(2):248-73. https://doi. org/10.1097/ALN.0b013e31823c1030.

Bates C, Laciak R, Southwick A, Bishoff J. Over prescription of postoperative narcotics: a look at postoperative pain medication delivery, consumption and disposal in urological practice. J Urol. 2011;185(2):551-5. https://doi.org/10.1 016/j.juro.2010.09.088

Bohnert AS, Valenstein M, Bair MJ, Ganoczy D, et al. Association between opioid prescribing patterns and opioid overdose-related deaths. JAMA. 2011;305(13): 1315-21. https://doi.org/10.1001/jama.2011.370 PMID: 21467284.

Brat GA, Agniel D, Beam A, et al. Postsurgical prescriptions for opioid naive patients and association with overdose and misuse: retrospective cohort study. BMJ. 2018;360:j5790. Published 2018 Jan 17. https://doi.org/10.1136/ bmj.j5790.

Centers for Disease Control and Prevention. 2019 Annual surveillance report of drug-related risks and outcomes-United States. Surveillance Special Report 2. Centers for Disease Control and Prevention, U.S. Department of Health and Human 31 Services. Available at: https://www.cdc.gov/drugoverdose/pdf/ pubs/2019-cdc-drug-surveillance-report.pdf Accessed 12 Dec 2020.

Chen EY, Marcantonio A, Tornetta P 3rd. Correlation between 24-hour predischarge opioid use and amount of opioids prescribed at hospital discharge. JAMA Surg. 2018;153(2):e174859. https://doi.org/10.1001/jama surg.2017.4859.

Dowell D, Haegerich TM, Chou R. CDC guideline for prescribing opioids for chronic pain-United States, 2016. MMWR Recomm Rep. 2016;65(RR-1):1-49. https://doi.org/10.15585/mmwr.rr6501e1externalicon.

Hill MV, McMahon ML, Stucke RS, Barth RJ Jr. Wide variation and excessive dosage of opioid prescriptions for common general surgical procedures. Ann Surg. 2017;265(4):709-14. https://doi.org/10.1097/SLA.0000000000001993.

Hupp JR. The surgeon's roles in stemming the prescription opioid abuse epidemic. J Oral Maxillofac Surg. 2016;74(7):1291-3. https://doi.org/10.1016/j. joms.2016.05.001.

Hurley RW, Cohen SP, Williams KA, Rowlingson AJ, Wu CL. The analgesic effects of perioperative gabapentin on postoperative pain: a meta-analysis. Reg Anesth Pain Med. 2006;31(3):237-47. https://doi.org/10.1016/j.rapm.2006.01 005.

Levy B, Paulozzi L, Mack KA, Jones CM. Trends in opioid analgesic-prescribing rates by specialty, U.S., 2007-2012. Am J Prev Med. 2015;49(3):409-13. https:// doi.org/10.1016/j.amepre.2015.02.020.

Levy N, Quinlan J, El-Boghdadly K, Fawcett WJ, et al. An international multidisciplinary consensus statement on the prevention of opioid-related harm in adult surgical patients. Anaesthesia. 2021;76(4):520-36. https://doi. org/10.1111/anae.15262 Epub 2020 Oct 7. PMID: 33027841

Militsakh O, Lydiatt W, Lydiatt D, Interval E, Lindau R, Coughlin A, et al. Development of multimodal analgesia pathways in outpatient thyroid and parathyroid surgery and association with postoperative opioid prescription patterns. JAMA Otolaryngol Head Neck Surg. 2018;144(11):1023-9. https://doi. org/10.1001/jamaoto.2018.0987.

Rosero EB, Joshi GP. Preemptive, preventive, multimodal analgesia: what do they really mean? Plast Reconstr Surg. 2014;134(4 Suppl 2):85S-93S. https://doi. org/10.1097/PRS.0000000000000671.
Stern S, Trajtenberg M. Empirical implications of physician authority in pharmaceutical decision making. NBER Working Paper 6851. Cambridge: National Bureau of Economic Research; 1998.

Straube S, Derry S, McQuay HJ, Moore RA. Effect of preoperative Cox-II-selective NSAIDs (coxibs) on postoperative outcomes: a systematic review of randomized studies. Acta Anaesthesiol Scand. 2005;49(5):601-13. https://doi. org/10.1111/j.1399-6576.2005.00666.x.

Thiels CA, Ub DSI, Yost KJ, et al. Results of a prospective, multicenter initiative aimed at developing opioid-prescribing guidelines after surgery. Ann Surg. 2018;268(3):457-68. https://doi.org/10.1097/SLA.0000000000002919.

University of California San Francisco, Pain Management Committee's 2018. Opioid equivalent algorithm. Available at: http://links.Iww.com/ALN/B738.

\section{Publisher's Note}

Springer Nature remains neutral with regard to jurisdictional claims in published maps and institutional affiliations.
Ready to submit your research? Choose BMC and benefit from:

- fast, convenient online submission

- thorough peer review by experienced researchers in your field

- rapid publication on acceptance

- support for research data, including large and complex data types

- gold Open Access which fosters wider collaboration and increased citations

- maximum visibility for your research: over $100 \mathrm{M}$ website views per year

At $\mathrm{BMC}$, research is always in progress.

Learn more biomedcentral.com/submissions 